\title{
Interplay of Organizational Commitment and Job Performance in Academic Sector
}

\author{
* Altaf Hussain, Assistant Professor \\ ** Mohammad Hanif Khan, Assistant Professor \\ *** Muhammad Asad Khan, PhD Scholar
}

\begin{abstract}
This research study was meant to examine the relationship of organization commitment to job performance of academic staff. 320 academic staff was chosen for data collection using selfadministered questionnaires. Confirmatory factor analysis was performed using structural equation modeling (SEM). Assessment of both measurement and structural models of the study were performed. Strong and significant positive association between organizational commitment and job performance was documented among academic staff. The findings of study further corroborated that committed academic staff not only added up to their quality and devotion, but also improved their efficiency and delivery of service. Implications of the study were also discussed.
\end{abstract}

Keywords: Interplay, job performance, organizational commitment, universities, structural equation modeling

\section{Introduction}

In today's competitive world organizations have realized the importance and role of human resource in their success. Therefore, organizations primarily focus on their effectiveness, efficiency and proper utilization. In order to make them more efficient and effective, they need to be committed with their respective organizations. Increased commitment not only makes them loyal and devoted. But also make them to give more energy and achieve better for their respective organizations (Hafiz, 2017; Khan et al., 2010). Likewise universities also make every effort to make their academic staff more committed and loyal in order to improve their job performance.

Researchers elaborated organizational commitment as general attitude of employees toward their establishment (Porter, Steers, Mowday, \& Boulian, 1974). They further add that organizational commitment is psychological relationship of an employee with his/her organization. This relationship, if solid and strong, always help employee to stick to the organization and the intentions of quitting it is on the downside (Allen \& Meyer, 1996).

Job performance is a such set of actions which are taken by workers in order to fulfill the requirements of job description (Biswas \& Varma, 2012). Performance is the completion of tasks which make up one's job (Byars \& Rue, 2006). Performance is the outcome produces by an individual in a specific job during a specific period of time (Ladley, Wilkinson, \& Young, 2015). It is related directly to productivity which can be measured in terms of quality, quantity, efficiency and effectiveness (Rezaei, Çelik, \& Baalousha, 2011; Spangenberg, 1994).

It is obvious from the studies of various researchers that organizational commitment has strong link to job performance. Those employees who are psychologically, morally and emotionally attached with their respective organizations achieve more in comparison with those who have less or no commitment. Most of the studies have studied this relationship in industrial organizational settings while study of such a relationship is equal to naught in academic settings. Therefore, this study is aimed to find out this relationship in academic settings.

\section{Literature Review}

\section{Organizational Commitment and Employee Job Performance}

In the increased business competition organizations adopting the strategy that develops committed and loyal employees grasp the promising financial returns (Brown, McHardy, McNabb, \& Taylor, 2011; Huselid, 1995). A study of Camilleri (2002) considered organizational commitment of an

\footnotetext{
* Department of Commerce and Management Sciences, University of Malakand, Khyber Pakhtunkhwa, Pakistan Email: altafhussain@uom.edu.pk

** Department of Tourism and Hotel Management, University of Malakand, Khyber Pakhtunkhwa, Pakistan Email: hanifyousafzai@uom.edu.pk

*** Universiti Tun Hussein Onn (UTHM) Malaysia Email: asadkhanbte06@ gmail.com
} 
employee as one of the greater engine of business success. People centered strategy gives an organization a competitive advantage because people are inimitable asset unlike cost, technology and new product development. High performance business outcomes such as increased sales, profitability, improved productivity and less employee turnover generate as a result of committed and loyal employees (Dockel, Basson, \& Coetzee, 2006; Lesabe \& Nkosi, 2007; Rogers, 2001). These committed employees bind themselves to the organization's vision and mission. Organizational commitment of an employee has been considered as an important element in the delivery of good business results in a highly competitive environment (Mguqulwa, 2009). Employees' actual job performance has been linked with the organizational commitment and such linkage could be improved by the provision of training and development (Bartlett \& Kang, 2004). Employees' job performance could be more effective if the employee psychological attachment is enhanced by the organization and will lead to improve the work efficiency and helps organizations in getting competitive edge in the global environment (Hanif, 2013).

Organizational commitment is considered significant element which improves both individual as well as organizational performance (Khan, Ziauddin, \& Ramay, 2010). The literature suggests that academic staff performance could also be enhanced by contributing to their loyalty and devotion. The overall performance of universities depends upon the quality of academic staff and their level of organizational commitment (Rehman et al., 2013; Sabri, Ilyas, \& Amjad, 2011). Research associates the success of organization to committed and loyal employees. This study further reveals that high commitment environment of organizations helps reduce employee turnover, absenteeism, and operating cost at one hand while enhances employee job performance and efficiency on the other hand (Tolentino, 2013). Similarly, another study also demonstrates that strongly committed employees work harder and perform well in order to achieve organizational objectives (Meyer \& Allen, 2004; Tolentino, 2013). The association of affective commitment with job performance is justified theoretically through motivational argument. Those who are committed to organization's goals are supposed to work harder, perform better and consistent with the organizational expectations as compared to those who are not committed (Chelte \& Tausky, 1986; Meyer \& Allen, 2004; Tolentino, 2013; Zahra, 1984).

Similarly, another similar study has established a link of affective commitment with increased worker's job performance. A study by Vandenberghe, Bentein, and Stinglhamber (2004) found that the organizational commitment and supervisor's commitment are related to employee job performance and intent to quit. A study conducted in industrial units of Jordan demonstrated a positive association between organizational commitment and its three components with work performance of employees (Suliman \& Iles, 2000). Another research which carried out on employees of oil and gas sector revealed a positive association between organizational commitment and job performance. This study further demonstrated that among the three components of organizational commitment, normative commitment is positively and significantly related to the job performance of workers (Khan et al., 2010; Memari, Mahdieh, \& Marnani, 2013). Another similar study conducted on faculty members in academic settings of Pakistan also revealed that committed faculty members performance are better in comparison to those staff members having less commitment to the universities (Chughtai \& Zafar, 2006). In similar vein, a recent study conducted in banking sector of Pakistan also discovered positive association between organizational commitment and work performance of workers (Hafiz, 2017). However, mostly industrial organizational psychologists have investigated association between employees' job performance and organizational commitment (Tolentino, 2013; Hafiz, 2017) while researchers have almost ignored the research on the association of these two variables in academic settings. Bearing this in mind, this study will further validate the results of the previous studies vis-à-vis the relationship of these variables.

\section{Methodology}

This study was quantitative in nature. We collected data from faculty members of seven public universities of Peshawar division, KP, Pakistan. A questionnaire survey was used as a tool to collect the data. Sample consists of 320 faculty members. Within probability sampling, stratified random sampling was employed in the study. Such sampling technique was used to ensure equal representation of each academic staff, i.e. male and female and university. Reliable and valid measuring instruments were used taken from the studies of previous researchers (Valaei \& Rezaei, 
2016; Yusoff, Ali, \& Khan, 2014). More specifically, Goodman and Svyantek (1999)'s study was used to give items for the job performance instrument. Organizational commitment instrument was taken from Meyer and Allen (1997). AMOS-23 was employed for data analysis of study.

\section{Data Analysis}

Data were analyzed by using structural equation modelling including confirmatory factor analysis (CFA).Two variables operationalized in the study were found reliable and valid. These variables' reliability was checked utilizing three different elements i.e. factor loadings, composite reliability (CR) and average variance extracted (AVE). Detailed results are mentioned in Table1.

For determination of validity of measurement model, both convergent and discriminant validity was employed. The AVE values for all variables were recorded as $0.75,0.73,0.68$, and 0.57 qualifying the sufficient convergent validity. (Refer toTable1).

Table1: Items loadings, composite reliability and average variance extracted

\begin{tabular}{|c|c|c|c|c|c|}
\hline Constructs & Items & Factor Loadings & $\mathbf{R}^{2}$ & $\begin{array}{l}\text { CR } \\
\text { (Above 0.6) }\end{array}$ & $\begin{array}{l}\text { AVE } \\
\text { (Above } 0.5 \text { ) }\end{array}$ \\
\hline \multirow{6}{*}{ Continuance commitment } & $\mathrm{CC} 1$ & 0.61 & 0.37 & \multirow{6}{*}{0.85} & \multirow{6}{*}{0.75} \\
\hline & $\mathrm{CC} 2$ & 0.68 & 0.46 & & \\
\hline & $\mathrm{CC} 4$ & 0.67 & 0.46 & & \\
\hline & CC5 & 0.67 & 0.45 & & \\
\hline & CC6 & 0.83 & 0.69 & & \\
\hline & $\mathrm{CC} 7$ & 0.80 & 0.64 & & \\
\hline \multirow{6}{*}{ Normative commitment } & $\mathrm{NC} 1$ & 0.76 & 0.58 & \multirow{7}{*}{0.89} & \multirow{6}{*}{0.73} \\
\hline & $\mathrm{NC} 2$ & 0.72 & 0.52 & & \\
\hline & NC3 & 0.75 & 0.58 & & \\
\hline & $\mathrm{NC} 4$ & 0.81 & 0.66 & & \\
\hline & NC5 & 0.74 & 0.54 & & \\
\hline & NC6 & 0.75 & 0.56 & & \\
\hline \multirow{5}{*}{ Affective commitment } & $\mathrm{AC} 2$ & 0.73 & 0.53 & & \multirow{5}{*}{0.68} \\
\hline & AC3 & 0.62 & 0.39 & \multirow{4}{*}{0.81} & \\
\hline & $\mathrm{AC} 4$ & 0.69 & 0.48 & & \\
\hline & AC5 & 0.60 & 0.36 & & \\
\hline & AC6 & 0.75 & 0.56 & & \\
\hline \multirow{11}{*}{ Job performance } & JP1 & 0.73 & 0.53 & \multirow{11}{*}{0.90} & \multirow{11}{*}{0.57} \\
\hline & JP2 & 0.73 & 0.56 & & \\
\hline & JP3 & 0.75 & 0.56 & & \\
\hline & JP4 & 0.64 & 0.41 & & \\
\hline & JP5 & 0.64 & 0.51 & & \\
\hline & JP6 & 0.60 & 0.36 & & \\
\hline & JP7 & 0.71 & 0.51 & & \\
\hline & JP8 & 0.73 & 0.54 & & \\
\hline & JP9 & 0.66 & 0.43 & & \\
\hline & JP10 & 0.56 & 0.31 & & \\
\hline & JP15 & 0.62 & 0.38 & & \\
\hline
\end{tabular}

Discriminant validity was determined using Fornell and Larcker (1981) criterion. According to this criterion, all the AVE values (diagonal) were higher than the squared construct correlation values (off diagonal), recording the sufficient discriminant validity. (Refer to Table).

Table 2: AVE and SIC values

\begin{tabular}{lllll}
\hline & $\mathbf{A C}$ & $\mathbf{C C}$ & $\mathbf{N C}$ & JP \\
\hline $\mathbf{A C}$ & $\mathbf{0 . 8 2 4}$ & & & \\
$\mathbf{C C}$ & .547 & $\mathbf{0 . 8 5 4}$ & & \\
$\mathbf{N C}$ & .537 & .599 & $\mathbf{0 . 8 5 4}$ & \\
$\mathbf{J P}$ & -.263 & -.277 & -.321 & \\
& .367 & .426 & .422 & $\mathbf{0 . 8 2 5}$ \\
\hline
\end{tabular}

Structural equation modelling (SEM) is a second generation technique which is developed to analyze inter relationships among multiple variables simultaneously in a model (Awang, 2015). SEM 
was used to run the regression pathways. Resultantly, an empirical structural model was developed for the current study. Figure 1 shows the results of the structural model.

Model fitness was assessed using measures of both absolute fit index and incremental fit index. Structural model was found fit using four measures of absolute fit index, i.e. Chi-square/ DF, GFI, RMSEA and RMR. Incremental fit index for the structural model were determined using three measures, i.e. CFI, NFI and TLI. The values for all these measures were found within the acceptable range, confirming the goodness of fit for the structural model. It was also concluded that proposed model was found fitted well. Detailed results are mentioned in Table 3.

Table3: Statistics for model fitness

\begin{tabular}{ll}
\hline Chi-square (CMIN) & 1450.8 \\
\hline Degree of freedom (DF) & 965 \\
CMIN/DF & 1.502 \\
Goodness of fit index (GFI) & .888 \\
Root mean square error of approximation (RMSEA) & .041 \\
Normed fit index (NFI) & .883 \\
Root mean square residual (RMR) & .063 \\
Comparative fit index (CFI) & .957 \\
Tucker Lewis index (TLI) & .954 \\
\hline
\end{tabular}

The values of squared multiple correlations $\left(\mathrm{r}^{2}\right)$ are above 0.35 , showing the maximum power of variance for the overall model.

The association between organizational commitment and job performance was investigated. The effect of organizational commitment on the job performance was determined using beta coefficient. The standardized beta coefficient from organizational commitment to job performance was 0.74 , indicating the positive and significant effect $(\mathrm{p}<0.001)$. (Refer Figure 1). Hypothesis formulated in the study is strongly supported by the empirical data.

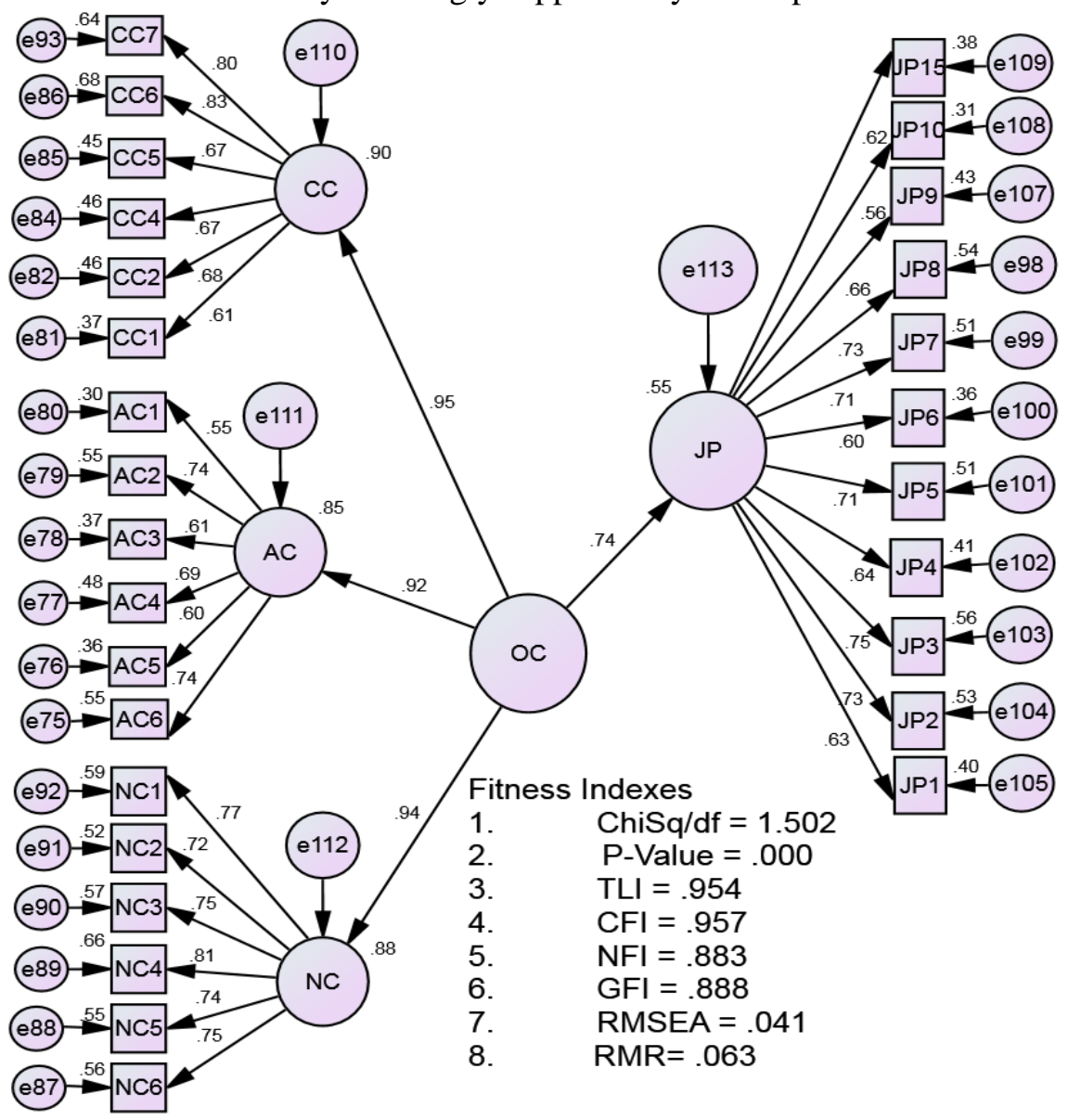

Figure 1: Structural model showing standardized regression weights between constructs 


\section{Discussion}

The prediction of positive relationship between the two variables was supported after data analysis. The results showed that organizational commitment and job performance are positively related with each other. Such results are in congruence with the results of previous studies such as (Hafiz, 2017; Khan et al., 2010; Memari et al., 2013; Meyer \& Allen, 2004; Tolentino, 2013). Results of the study reflect the organizational commitment to be an important element for both the improvement of individual and organizational performance. More importantly, the findings of the study further demonstrate that university academic staffs performance could also be enhanced by contributing to their loyalty and devotion. The overall performance of universities mostly depends upon the quality of academic staffs and their level of organizational commitment. Research links the accomplishment of an organization to the employees' organizational commitment. This study further reveals that high commitment environment of organizations helps reduce employee turnover, absenteeism and operating cost at one hand while enhances employees' efficiency and job performance on the other hand (Tolentino, 2013). It is also revealed in several studies that employees with enhanced organizational commitment perform better in order to achieve organizational objectives (Hafiz, 2017; Khan et al., 2010; Memari et al., 2013; Meyer \& Allen, 2004; Tolentino, 2013). The same is true for university academic staffs if they have more organizational commitment, they would exert more efforts and perform better in order to achieve objectives set by their respective universities.

\section{Conclusion, recommendations and limitations}

This study corroborates the importance of organizational commitment both to the individual and organizational performance. It is concluded that committed academic staff work efficiently and effectively and their performance is better when compared with those academic staff who are noncommitted. Organizational commitment helps improve their loyalty and devotion with the universities and enhance their role in the success and stability of universities and their delivery of service. It is also revealed that high commitment environment helps improve efficiency, effectiveness and the job performance of academic staff.

The findings of the study suggest to university management to specifically consider those academic staff which are poor performer. If they intend to improve their performance and efficiency, current study's findings could be of great help and benefit.

Cross sectional and survey based nature is one of limitations of the current study. Another limitation of the study is the investigation of direct effect of organizational commitment on the job performance of academic staff. It is suggested that future research can include prospective mediator and moderator along with the current variables. Furthermore, a Survey based quantitative research design was used in this, therefore it is expected that future research work can consider triangulation method to broaden the generalizability of the research work.

\section{References}

Allen, Natalie J, \& Meyer, John P. (1996). Affective, continuance, and normative commitment to the organization: An examination of construct validity. Journal of vocational behavior, 49(3), 252-276.

Awang, Z. (2015). SEM Made Simple: A Gentle Approach to Learning Structural Equation Modeling: MPWS Rich Publication.

Bartlett, Kenneth, \& Kang, Dae-seok. (2004). Training and organizational commitment among nurses following industry and organizational change in New Zealand and the United States. Human Resource Development International, 7(4), 423-440.

Biswas, Soumendu, \& Varma, Arup. (2012). Linkages between antecedents of in-role performance and intentions to quit: an investigation in India. The International Journal of Human Resource Management, 23(5), 987-1005.

Brown, Sarah, McHardy, Jolian, McNabb, Robert, \& Taylor, Karl. (2011). Workplace performance, worker commitment, and loyalty. Journal of Economics \& Management Strategy, 20(3), 925955.

Byars, A, \& Rue, E. (2006). Human Resource Management: Contemporary Issues, Challenges and Opportunities. New Jersey: IAP.

Camilleri, Emanuel. (2002). Some antecedents of organizational commitment: Results from an information systems public sector organization. Bank of Valletta Review, 25, 1-29. 
Chelte, Anthony F, \& Tausky, Curt. (1986). A Note on Organizational Commitment Antecedents and Consequences among Managers, Professionals, and Blue-Collar Workers. Work and Occupations, 13(4), 553-561.

Chughtai, Aamir Ali, \& Zafar, Sohail. (2006). Antecedents and consequences of organizational commitment among Pakistani university teachers. Applied H.R.M Research, 11(1), 39-64.

Dockel, Andreas, Basson, Johan S, \& Coetzee, M. (2006). The effect of retention factors on organisational commitment: An investigation of high technology employees. SA Journal of Human Resource Management, 4(2), 20-28.

Goodman, Scott A, \& Svyantek, Daniel J. (1999). Person-organization fit and contextual performance: Do shared values matter. Journal of Vocational Behavior, 55(2), 254-275.

Hafiz, AZ. (2017). Relationship between Organizational Commitment and Employee's Performance Evidence from Banking Sector of Lahore. Arabian Journal of Business and Management Review 7(2), 1-7.

Hanif, Furqan. (2013). Impact of training on employee's development and performance in hotel industry of lahore, pakistan. Journal of business studies quarterly, 4(4), 68-82.

Huselid, Mark A. (1995). The impact of human resource management practices on turnover, productivity, and corporate financial performance. Academy of management journal, 38(3), 635-672.

Khan, Muhammad Riaz, Ziauddin, Jam FA, \& Ramay, MI. (2010). The impacts of organizational commitment on employee job performance. European Journal of Social Sciences, 15(3), 292298.

Ladley, Daniel, Wilkinson, Ian, \& Young, Louise. (2015). The impact of individual versus group rewards on work group performance and cooperation: A computational social science approach. Journal of Business Research, 68(11), 2412-2425.

Lesabe, Rankgoang Andrew-Face, \& Nkosi, James. (2007). A qualitative exploration of employees' views on organisational commitment. SA journal of human resource management, 5(1), 3544.

Memari, Negin, Mahdieh, Omid, \& Marnani, Ahmad Barati. (2013). The impact of Organizational Commitment on Employees Job Performance." A study of Meli bank". Interdisciplinary journal of contemporary research in business, 5(5), 164-171.

Meyer, John P, \& Allen, Natalie J. (1997). Commitment in the Workplace: Theory, Research, and Application: SAGE Publications.

Meyer, John P, \& Allen, Natalie J. (2004). TCM employee commitment survey academic users guide 2004. London, Ontario, Canada: The University of Western Ontario, Department of Psychology.

Mguqulwa, Nomakhuze. (2009). The relationship between organisational commitment and work performance in an agricultural company.

Porter, Lyman W, Steers, Richard M, Mowday, Richard T, \& Boulian, Paul V. (1974). Organizational commitment, job satisfaction, and turnover among psychiatric technicians. Journal of applied psychology, 59(5), 1-21.

Rehman, Khalid, Rehman, Z, Saif, N, Khan, AS, Nawaz, A, \& Rehman, S. (2013). Impacts of job satisfaction on organizational commitment: a theoretical model for academicians in HEI of developing countries like Pakistan. International Journal of Academic Research in Accounting, Finance and Management Sciences, 3(1), 80-89.

Rezaei, A. R., Çelik, T., \& Baalousha, Y. (2011). Performance measurement in a quality management system. Scientia Iranica, 18(3), 742-752.

Rogers, Edward W. (2001). A theoretical look at firm performance in high-tech organizations: what does existing theory tell us? The Journal of High Technology Management Research, 12(1), 39-61.

Sabri, Pirzada Sami Ullah, Ilyas, Muhammad, \& Amjad, Zahra. (2011). Organizational culture and its impact on the job satisfaction of the University teachers of Lahore. International Journal of Business and Social Science, 2(24), 121-128.

Spangenberg, HH. (1994). Performance management-Problems and possible solutions. SA Journal of Industrial Psychology, 20(1), 1-6. 
Tolentino, Rebecca C. (2013). Organizational commitment and job performance of the academic and administrative personnel. International Journal of Information Technology and Business Management, 15(1), 51-59.

Valaei, Naser, \& Rezaei, Sajad. (2016). Job satisfaction and organizational commitment. Management Research Review.

Vandenberghe, Christian, Bentein, Kathleen, \& Stinglhamber, Florence. (2004). Affective commitment to the organization, supervisor, and work group: Antecedents and outcomes. Journal of vocational behavior, 64(1), 47-71.

Yusoff, Rosman Bin Md, Ali, Azlah Md, \& Khan, Anwar. (2014). Assessing reliability and validity of job performance scale among university teachers. Journal of Basic and Applied Scientific Research, 4(1), 35-41.

Zahra, SA. (1984). Managerial views of organizational politics. Management Quarterly, 25(1), 31-37. 